\title{
Impact of the Information Systems Management on the Effectiveness of Human Resources
}

\author{
Wiam Wahab Abdel-Hussein ${ }^{1, *}$ and Ali Khalaf Gatea ${ }^{1}$ \\ ${ }^{1}$ Southern Technical University, Technical Institute / Nasiriya, Iraq, Al-Nasiriya \\ *Corresponding author: WiamAl.yasiri@stu.edu.iq \\ https://doi.org/10.32792/utq/utj/vol15/1/2
}

\begin{abstract}
The research dealt with management information systems with their dimensions (recruitment subsystem, training subsystem, motivation subsystem) and their role in enhancing the efficiency and effectiveness of human resources in its dimensions (performance effectiveness, decision-making), and testing the relationship and influence between the dimensions of management information systems and the effectiveness of human resources in the research sample And knowing the extent to which the information environment provides in support of human resources and the extent of its contribution to achieving and enhancing employee inclusion.

Research applied to a sample consisting of (66) people from human resources personnel and used the questionnaire form as a tool for data collection. The importance of the research lies in that it came out with an intellectual background of the nature of its variables, and the need to develop, motivate and encourage human resources by clarifying how the organization works in a way
\end{abstract}


that contributes to knowledge and increases employee affiliation, and that management information systems are the interface of the organization in the governance of administrative decision-making, which can be Its way of clarifying the objectives of the organization and in line with its productive nature, whether service, industrial, educational or commercial.

Key word: Information systems, efficiency, human resources.

\section{INTRODUCTION:}

Administrative data system: In the light of globalization, the world is witnessing a profound and rapid development in the economic, political, social and technological fields. In view of the depth of this development and its speed in the field of information technology, the information has become an important place in the life of humanity and in all the special fields in the organizations. We address management information systems, which include preliminary concepts about the system and information to reach the comprehensive concept.

\section{THE CONCEPT OF MANAGEMENT INFORMATION SYSTEMS}

There are many views on the concept of management information systems (Ruwaili, 2014: 21). Management information systems are a set of procedures through which information can be provided to support decision-making and oversight processes in the organization. (Taha, 2008: 14) Administrative systems are a complete system, or a set of subsystems, whether it expresses all that the computer can offer in the field of management, or is one of the mechanical applications in the field of administration, while Loukis (1994:12) Management Information Systems (MIS) are a set of procedures, software, machines, compositions and curriculum science necessary to address Data retrieval and which are essential for the management of the organization, either (Salmi, 2005:45) has been known to management information systems is a set of inputs that represent the different data that is processed in order to obtain outputs that are essential to satisfy the responses required to achieve from the system.

1. Basic functions of information systems

The basic functions of the MIS can be identified (Hilton,1979:14) as follows:

a. Flexibility and ease of dealing, meaning no need for high-tech and procedural programming. 
b. User-oriented Data exchange is easy and logical for the user.

c. Have a high degree of security in terms of intra-departmental trading in the organization.

d. Take into account the changes in the organization, in terms of promotion, transfer and leaving the job.

\section{Characteristics of information}

Include the characteristics of the information as defined (Alouti, 2008: 108)

a. Relevance: - In the sense that the information is compatible with the purpose for which it was prepared.

b. Timely: - the provision of information in a timely manner, so that it is available when needed.

c. Ease and clarity: - In the sense that the information is clear and understandable to its users.

d. Health and accuracy: - The right information means to be real information about what you express.

e. collection: - in the sense that the information provided complete information, that is to cover all aspects of its users.

f. Acceptance: - In the sense that the information is provided in the image and the means that the user accepts in terms of form and content.

\section{HUMAN RESOURCES}

Human Resources: Researchers and Authors differed in the definition of human resources. (Al-Lozi, 2000: 87) defines human resources as the preparation of the human element correctly in accordance with the needs of society on the basis that by increasing the knowledge and ability of man, (Maher, 2004: 24). Human resources are the series of decisions on functional relationships affecting the effectiveness of the organization and the workers. (Dessler, 2003: 35) Human resources are defined as the relationship between individuals and the strategic objectives of the organization for the purpose of Improve its performance and fold The researchers believe that HR is a term to describe formal systems that have been developed for individuals within an organization that focus on recruiting, managing and directing people working in the organization to achieve their goals.

1. Human Resources Functions

There are many administrative and executive functions that are the responsibility of the human resources of the Organization:

1.1. Administrative functions: They can be summarized as follows: 
a. Planning: - 1999: 58 (Kacmar, \& Anthony) Planning the decision-making process of access to use and development of human resources.

b. Organization: - The organization defines the form of the organizational structure of human resources by designing the work structure between the work, individuals, physical factors of the organization (Shawish, 2005: 132)

c. Guidance: Al-Alouti, 2008: 149). Guidance is the process of directing individuals' efforts towards achieving the objectives of the organization. This function may fall under several names including Motivation or Command. The purpose of this function is to encourage individuals to work with complete and effective satisfaction.

d. Performance evaluation: - Evaluation of the performance of individuals means their order descending or ascending according to their abilities and personal experience This includes the function of the Human Resources Department to collect information on behavior and performance as well as determine the actual performance levels and finally assess performance by focusing on the strengths and weaknesses to enhance the second and try to address the first , (Hitti, 2003: 36)

1.2. Executive functions:

The executive functions of human resources management are divided into four functions, the polarization process is one of the most important functions of human resources management through polarization.

a. For individuals, the system is concerned with the demographic and functional data related to them.

b. Training and development of employees: - The objective of training to increase the efficiency and effectiveness of the workforce through the provision of all the requirements, the preparation of training programs to enable individuals to accomplish their work successfully. (Al-Ruwaili, 2014: 67)

c. Compensation or reward function: - An important function of human resources management is the reason for the direct impact on the standard of living of employees as a significant proportion of the cost of the worker in most organizations.

d. Care and maintenance of human resources: - through the provision of health care, cultural, recreational and social, also care after leaving the service. (Shawish, 2005: 181)

\section{PREVIOUS RESEARCH}


1. (Madhoun, 2007) The efficiency of administrative information systems in the effectiveness of human resources in the Ministry of the Palestinian Authority, and the most important factors that limit Of the efficiency and impact on the effectiveness of human resources The research presented a set of proposals that can in turn contribute to improving the efficiency of management information systems, so that they can play their role in providing appropriate information on which the management of human resources in decision-making, The audit of the information used for human resources information systems, and that the most important reasons for the low efficiency of administrative information systems is one of the most important factors affecting the effectiveness of human resources.

2. (zafar,2012) explore the basics of information security and its relevance to the organization. In view of the increasing use of systems in institutions, the research revealed how to maintain the security of these systems and enhance their relevance to the performance of the organization., And the research showed that the most important determinants of security of these systems are: risk analysis, training, integration, policies, data evaluation, and system structure.

3. Research: (Gergana 2012): aimed at investigating the appropriate conditions of human resources management information systems and their impact on organizational competitiveness, as these systems are the basis in building the dynamic capabilities of the organization, and thus enhance their ability to replicate their success. The research concluded that information systems Human resources are the key to building the necessary capacity for competitive competitiveness in the organization.

4. (Al-Ruwaili, 2014) The Role of Administrative Information Systems in the Effectiveness of Human Resources A Field Study at the Ministry of Interior in Bahrain: The aim of the research was to identify the reality of both the efficiency of administrative information systems and the level of performance of human resources. Demographic Variables of HR Personnel (Gender, Age, Occupation, Years of Experience) The research found that there is a strong influence between the administrative information systems and the effectiveness of the human resources of the Ministry of Interior in Bahrain.

\section{METHODOLOGY}

The human resources environment has undergone many changes, the most complex being the introduction of management information systems. This development has brought about a significant change in human resources as a center for reducing costs and also a center 
of profitability. Therefore, the successes of our modern world have not been coincidental, The administrative leaders are wise in managing their organizations towards achieving general and specific goals.

1. Research problem: It can be said that the problem of research is to reveal the relationship between the administrative information systems and the administrative role of human resources, as well as to identify the procedures for increasing the effectiveness of human resources through the use of administrative information systems and techniques in organizations. The problem of research can be summarized in a number of the following questions:

A. To what extent do MIS affect the effectiveness of human resources?

B. Lack of interest in administrative motivation as a guide to increase the functionality of human resources.

C. Is there a relationship between management information systems and human resources?

2. research importance

A- A statement of the importance of switching to the automation of management information systems related to the human resource and the mechanism of remote work using computer as an input to improve the performance of human resources function.

B - The importance of the research from being looking at the nature of the relationship in the application of management information systems in the organization and its impact on the effectiveness of human resources.

C - Statement of the level of effectiveness of human resources and the status of the status of the level of management information systems in the organization in question.

3. research goals

(A) Highlighting the impact of management information systems on the effectiveness of human resources.

(B) To identify the extent to which management information systems are being applied in the organization in question.

C) To make a set of recommendations in light of the findings of the research.

4. research assumes:-

The research includes a key premise that "FAO's management information systems affect the increased and enhanced effectiveness of the Organization's human resources"

(Sub-system of polarization, sub-system of training, sub-system of motivation) and human resources by its exclusion (effectiveness of performance, decision making). 
5. search limits

a. Spatial boundaries: The research at the Technical Institute - Nasiriyah was confined to the field of research.

b. Human boundaries: The sample was selected randomly (represented by a group of human resource managers).

\section{THE APPLIED SIDE}

The administrative information systems are the first tool in the administration's hands to provide the data and information on which decisions are based and as a result must be designed in accordance with the nature of the administrative work in the organization as well as the objectives to be achieved, taking into account the size of the organization and the number of its employees. And the activation of human resources operating within the framework of the organization, a survey questionnaire was prepared for a number of employees who hold different jobs at different levels in an academic educational institution (NASS) This form was prepared in accordance with the educational and functional level of the research sample, through which the validity of the research hypothesis and the possibility of proving it can be measured by analyzing their responses through the SPSS program and its statistical tools.

\section{DISCUSSION :}

After the completion of the practical side and statistical analysis by the program spss and statistical tools that are accurate and shown in the previous tables show the following results:

1. The Alpha-Cronbach coefficient gives a score of (0.812) of reliability in the survey resolution paragraphs, a score that is very acceptable to the statistical program inputs and indicates the accuracy of the answers collected from the sample in terms of table (3-2).

2. The degree of influence of the administrative information systems in increasing the effectiveness of human resources is positive and at a significant level of significance (0.05) in terms of table (3-7).

3) that there is a positive correlation between the level of significance of (0.01) by Pearson correlation coefficient, which indicates the validity of the hypothesis of the research in terms of Table (3-8). 
4. The research sample is a distinct mixture of managerial experience, leadership levels and academic level, which was collected in a course to develop human resources at various levels. - $\quad$ The most important conclusions reached by the researchers are:

1. The Organization's human resources have the minimum knowledge requirements for the Organization's Management Information Systems (MIS) but fail to explain and explain the evaluation paragraphs used in the annual evaluation.

2. The level of knowledge in the research sample has greatly helped in diagnosing the positive and negative aspects in the application of administrative information systems, through which they can enhance their effectiveness and overcome the obstacles that may cause the decline in productivity.

3. There is a semi-consensus among the research sample in the need to develop, motivate and encourage human resources by clarifying how the administrative work in the organization contributes to knowledge and increases the functional affiliation of employees.

- $\quad$ Based on the findings, researchers can recommend:

1. Management information systems are the organization's interface in the management decision-making, through which the objectives of the organization can be clarified in accordance with its productive nature, be it service, industrial, educational or commercial.

2. The necessity of applying administrative information systems in a manner consistent with the organizational and administrative nature of the organization, which is based on the structure of administrative information systems.

3. The need to introduce workers in institutions in development courses to increase administrative knowledge and productivity and in accordance with the nature of the work assigned to it.

4. Establish workshops to explain the decision-making mechanism related to employees according to the data provided by the management of the administrative information systems applied in the organization.

5. Opening the door to researchers at different levels to study the administrative information systems applied in the institutions to diagnose positive aspects and enhance them and negative aspects to avoid them in order to achieve the maximum possible productivity of human resources working in them.

6. The promotion and encouragement of workers is not necessarily a material encouragement, but it can be administrative and organizational, which generates the feeling of employees that they are part of the organization and that the effort is estimated by the senior management, 
whether by way of rewards or books of thanks and appreciation and guarantee financial rights and evaluation on scientific and administrative basis Right away from patronage.

Reference :

- Taha, Tariq Ahmad, 2008, Management Information Systems and Computer Systems (from a Contemporary Administrative Perspective), University Thought House, Alexandria.

- Al-Salami, Alaa Abdul Razzaq Mohammed, 2005, Electronic Management Networks, Dar Wael for Publishing, I, Amman, Jordan.

- Al-Lozi, Musa, 2000, Administrative Development: Concepts, Principles, Applications, 1, Dar Wael Publishing and Distribution, Amman, Jordan.

- Maher, Ahmed, 2004, Human Resources Management, University House, Alexandria, Egypt.

- Shawish, Mostafa Najib, 2005, Human Resources Department, Dar Al Shorouk, Amman, Jordan.

- Al-Hitti, Khalid Abdul Rahim, 2003, Human Resources Management: Strategic Approach, Dar Wael Publishing and Distribution, Amman, Jordan.

- Aqili, Omar, 2004 (Contemporary Human Resource Management) Strategic Dimension, Dar Wael, Amman.

- Al-Ruwaili, Emad Safouk Glud, 2014, "The Role of Management Information Systems in Increasing the Effectiveness of Human Resources in the Kingdom of Bahrain".

- Madhoun, Mohamed, Amal Abu Rahma, 2007, "The Effectiveness of Human Management Information Systems in the Ministries of the Palestinian Authority".

- Eloti, Jane, 2008, "The Impact of Information and Communication Technologies on Human Resource Management in the Organization", Algeria.

- An Anthony, P.Perrevus \& Kacmar, K. m. Human Resource Management Astratic Approach, New York: The Dryden press (1999).

- D Dessler, Gary (2003), Human Resource Management 9th edition (Newjersey: Prentice Hall).

- G Gergana, Markova, 2012. Building Dynamic Capabilities: The Case of HRIS, Management Research: The Journal of the Iberoamerican Academy of Management, 10 (2): 81-98.

- Hilton Hilton, Thomas, 1979: Information Systems Ethics: A Practitioner Survey, 14.

- Z Zafar, Humayun, 2012: Human Resource Information Systems: Information, Security Concerns for Organizations, Human Resource Management Review, HUMRES-00426; No of P9. 